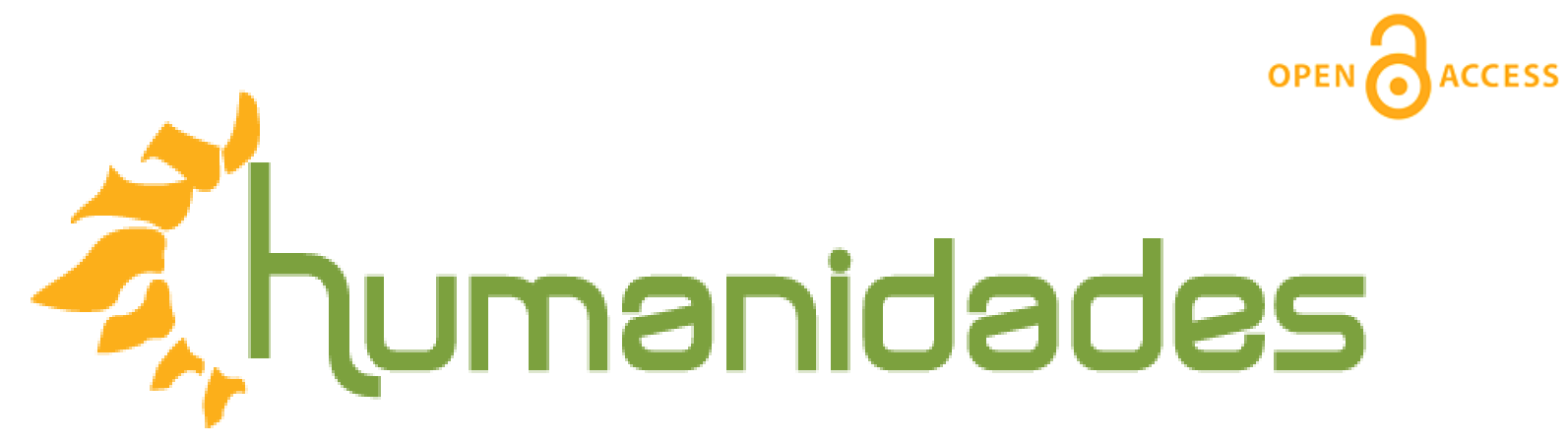

Revista de la Escuela de Estudios Generales, Universidad de Costa Rica

Julio-diciembre, 2016 • Volumen 6, número 2 • EISSN 2215-3934• pp. 1-8

\title{
Detrás del trono (Un viaje filosófico por el pecado, el delito y la culpa)
}

DOI: http://dx.doi.org/10.15517/h.v6i2.26752

\section{Alicia Gurdián Fernández}

Investigadora jubilada del Instituto de Investigación en Educación (INIE), Universidad de Costa Rica.

Correo electrónico: agurdianf@gmail.com

Todos los derechos reservados. Universidad de Costa Rica. Esta revista se encuentra licenciada con Creative Commons. Reconocimiento-NoComercial-SinObraDerivada 3.0 Costa Rica.

Correo electrónico: humanidades@ @ucr.ac.cr / Sitio web: http://revistas.ucr.ac.cr/index.php/humanidades 


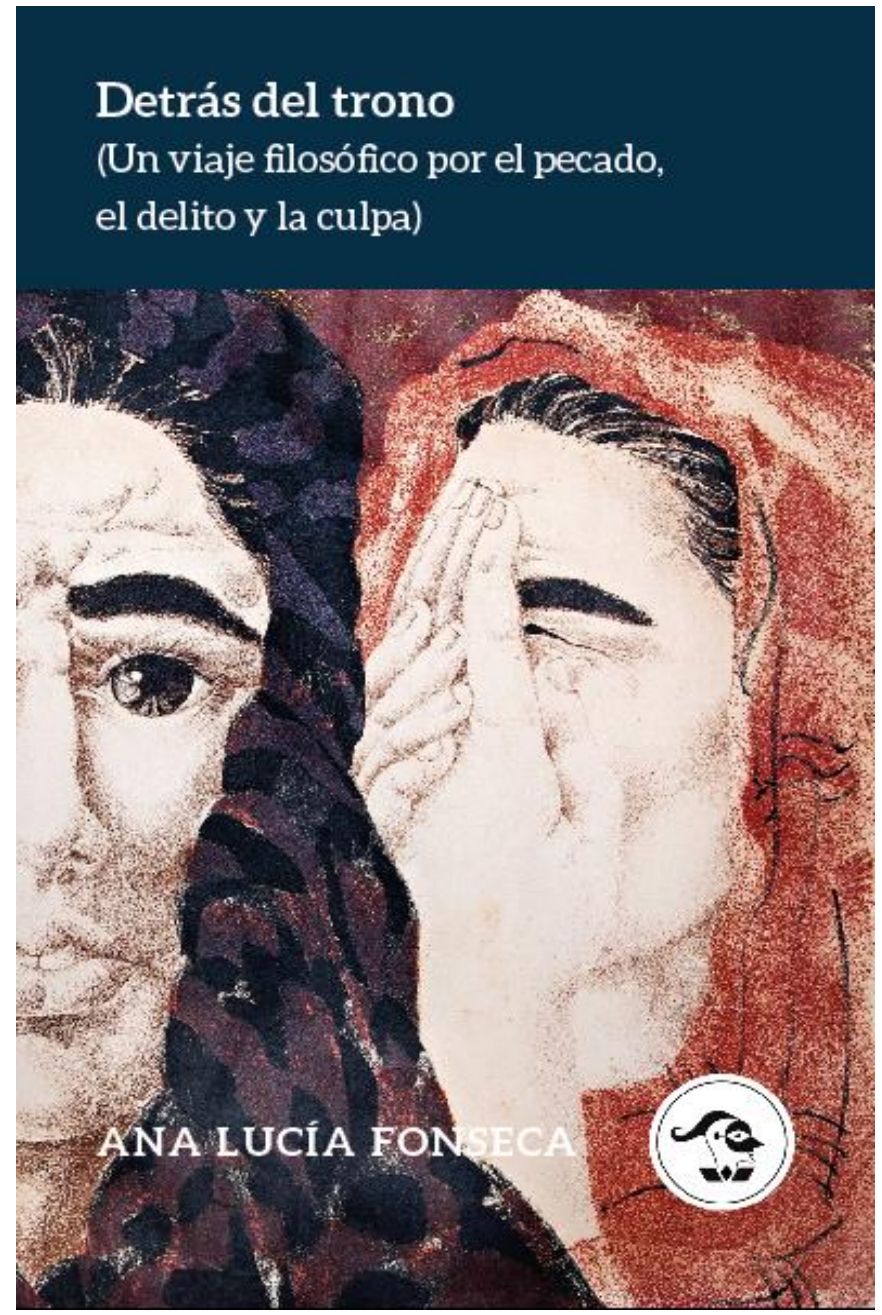

Ana Lucía Fonseca Ramírez Detrás del trono (Un viaje filosófico por el pecado, el delito y la culpa) San José, Costa Rica: Editorial Arlekín, 2015. ISBN: 978-9968-681-20-9 
El libro Detrás del trono (Un viaje filosófico por el pecado, el delito y la culpa), que nos obsequia Ana Lucía Fonseca Ramírez, puede ser considerado una obra que provoca. Se trata un ensayo transgresor, sobre todo en una sociedad de doble moral como la costarricense, en el cual se muestra, como bien lo señala Alexander Jiménez en la contraportada del libro, "uno de los modos deseables de ejercitar el oficio de la Filosofía en un país como Costa Rica".

¿Cuál puede ser un acercamiento y diálogo con el texto? En su ensayo, Ana Lucía nos invita a compartir con ella su viaje; para eso, nos brinda un mapa en el que se representan cuatro rutas:

1. Pecado: ¿Una ofensa a Dios?

2. Delito: Las tablas de la Ley

3. El cuerpo tutelado

4. Hacia una moral sin pecado

$\mathrm{Al}$ respecto, nos advierte que se internó en una trama religiosa caracterizada por la confusión entre el pecado y el delito. Viajó, como ella bien lo señala, por los meollos ideológicos expresados en el pensamiento teocrático, ideología que confunde los órdenes de lo religioso y lo político. Esto la llevó a cuestionar sus creencias e incredulidades, razones por las cuales experimentó una confrontación filosófica con su propia vida y la sociedad en donde vive. 
¿Por qué es peligrosa la confusión entre el pecado y el delito?, ¿qué la motivó a cuestionarse sus creencias e incredulidades?, ¿por qué esa confrontación filosófica?, ¿tiene esto algo que ver con nuestra historia de vida individual y colectiva?

Es relevante hacer un paréntesis para subrayar que se trata de un libro que debe ser leído con calma y haciendo notas al margen, puesto que invita a revisar conceptos ya conocidos y a aprender nuevos; invita a ver con atención nuestro mapa personal de viaje en el mundo de la vida. Por lo tanto, no está de demás un consejo, sobre todo para aquellas personas legas en la materia o que carecen del hábito de reflexionar sobre su historia de vida: elaborar una especie de bitácora o diario reflexivo es una práctica que ayudará en el viaje personal que se emprende, prácticamente, desde el inicio de la lectura de este libro, pues la introspección se impone desde el comienzo.

Ana nos hace tomar conciencia sobre la evolución del concepto pecado, desde su etimología hasta la amalgama doctrinal pecado-culpa, pasando por el discurso legitimador del castigo, por las disposiciones contra los herejes del Manual de Inquisidores, por las estrategias de la Contrarreforma y su expresión en el Concilio de Trento. Explora, luego, dos discursos sobre los delitos y la legitimación. Asimismo, profundiza en las nociones de delito y de pena o castigo, hasta sus supuestos fundantes. 
Es muy importante señalar que la meta de este recorrido, tanto teológico como jurídico, es arribar a la raíz religiosa que sostiene el discurso del poder: "el recurso a la potestad divina cambia solo aparentemente de registro cuando se invoca la potestad secular, pero el poder de juzgar y castigar sigue articulándose sobre la misma confusión" (2015, s. p.).

La trama religiosa del poder se evidencia también en los discursos de control social sobre la sexualidad y, con mayor énfasis, en los que legitiman el tutelaje del cuerpo femenino, apelando constantemente al amparo de la Única Moral, ruta de la tercera parte del viaje.

Continúa el texto con la cuarta ruta: "Hacia una moral sin pecado", donde Ana nos propone "una ética civil o ética sin víctimas... sin sacrilegios ni sacrificios, que asuma un planteamiento laico en relación con los valores y que sea capaz de fundamentar una moral sin pecado" (2015, s. p.). Se trata de una ética para ciudadanas y ciudadanos empeñados en organizar sus vidas en común, fuera de ficciones atemorizantes y opresivas, tal como destaca Alexander Jiménez también en la contraportada.

Es primordial tener presente que la discriminación, con su jerarquía basada en las diferencias biológicas de los seres humanos, tiene múltiples facetas: racismo, discriminación de género, de personas con necesidades especiales, de personas enfermas, de minorías sexuales, de niñas y niños, adolescentes y personas mayores. Todos esos modos de trato desigual tienen formas 
inorgánicas, orgánicas y oficiales. Las inorgánicas se manifiestan sin discursos y sin instituciones que las sustenten. Las orgánicas aparecen cuando se conforman y se asumen institucionalmente (como en la familia) los discursos que las respaldan. Y, por último, las formas oficiales, asumidas por el Estado como políticas. Por lo anterior, la sociedad jerarquizada amalgama todas las formas de discriminación: machismo, racismo, xenofobia, homofobia, entre otros.

Así las cosas, siguiendo a Ana Lucía, estamos ante "la urgencia de un Estado verdaderamente laico, ni antirreligioso ni confesional, pero tampoco neutral a la hora de defender la diversidad cultural, étnica, política, religiosa, sexual... es decir, la diversidad humana, no en el plano de las esencias, sino en el de las realidades sociales particulares, donde los sacrificios impuestos por la Moral de la Única Moral ha cobrado tantas vidas" (2015, p. 19).

Ahora bien, ¿cómo comprender aquello por lo que no preguntamos? Comparto algunas preguntas que pueden ayudar en el proceso de acercamiento y diálogo con el texto que nos ofrece Ana. Busqué en mi mochila de viaje y de ella surgieron primero preguntas y después algunos recursos.

¿Cómo asumir mi propio reto ante el pecado, el delito y la culpa?, ¿cuál será el propósito de mi viaje?, ¿qué debo cargar y qué es preciso desechar de mi mochila para emprender-comprender mi viaje?, ¿cuál será mi mapa?, ¿qué ruta o rutas seguiré?, ¿dónde, por qué y para qué me detendré a 
profundizar y a reflexionar?, ¿en cuáles de mis vivencias personales se han manifestado las artimañas y las falacias que sostiene el pensamiento teocrático?, ¿cuáles han sido las consecuencias de este pensamiento sobre nuestros cuerpos, nuestra sexualidad, nuestra subjetividad y nuestras formas convivencia? Incluso valdría preguntarse: ¿cuáles se aprecian sobre mi cuerpo, mi sexualidad, mi subjetividad y mi forma de convivir?

Hurgo en mi mochila y encuentro un recurso resguardado, pero que debo utilizar para continuar el proceso reflexivo. Invito a cuestionar y cuestionarse sobre tres aspectos que considero fundamentales, si realmente pretendemos asumir una posición ante lo planteado por Ana Lucía y, sobre todo, si hemos decidido emprender nuestro propio viaje:

1. ¿Cómo nos constituimos como sujetos de nuestro propio conocimiento?

2. ¿Cómo nos constituimos en sujetos frente a las relaciones de poder?

3. ¿Cómo nos constituimos como sujetos morales frente a nuestras propias acciones?

Tal vez se pregunten: ¿por qué recurrir la ontología histórica personal? Hacernos esas tres preguntas no solo implica una crítica sobre lo que digo/decimos, pienso/pensamos y hago/hacemos, sino también un recurso reflexivo sobre las complejas interacciones entre conocimiento, política y ética; de esa forma, es posible promover transformaciones personales y políticas, para una mejor convivencia. 
Mil gracias Ana Lucía por tu ejercicio de la filosofía plasmado en tan excelente libro, gracias por compartir tu viaje, gracias por invitarnos y, a la vez, provocarnos a asumir una posición ante el poder instalado Detrás del trono.

\section{¿Cómo citar este artículo?}

Gurdián, A. (Julio-diciembre, 2016). Detrás del trono (Un viaje filosófico por el pecado, el delito y la culpa). Revista humanidades, 6(2), 1-8. doi: dx.doi.org/10.15517/h.v6i2.26752 